\title{
Celso Emilio Ferreiro: voz de un tiempo y una tierra a los cien años de su nacimiento'
}

\author{
Celso Emilio Ferreiro: voice of a time and a land, \\ a century from his birth
}

\author{
RAMÓN NICOLÁS RODRÍGUEZ \\ Fundación Celso Emilio Ferreiro \\ España \\ rnicolas@edu.xunta.es
}

\begin{abstract}
Se celebra en Galicia el centenario del nacimiento de Celso Emilio Ferreiro y, sin duda, esta es una manera de hacer justicia a una de las figuras más destacadas del sistema literario gallego del siglo XX. Su obra ya no puede circunscribirse, únicamente, al poemario Longa noite de pedra, metáfora recurrente para simbolizar el largo período de la dictadura franquista. En Galicia se ha insistido especialmente este año en la singularidad de su personalidad literaria que va mucho más allá de ser el responsable de una de las voces que canalizaron, literariamente, la contestación al franquismo. Tal vez porque él mismo promovió ediciones bilingües gallego-castellanas de su obra, su proyección más allá de Galicia lo había convertido durante cierto tiempo en un poeta conocido y popular; esta resonancia es posible que se haya ido diluyendo para las generaciones más jóvenes de lectores en castellano. Por esta razón se ofrecen aquí algunas de sus claves bio-bibliográficas más elementales y, a continuación, un breve recorrido por la estética literaria que transitó.
\end{abstract}

\section{Perfil bio-bibliográfico ${ }^{2}$}

\section{Infancia y juventud}

Celso Emilio Ferreiro nació en Celanova (Ourense) el cuatro de enero de ı9ı2 según consta en su partida de nacimiento. Su madre lo trajo al mundo en la Rúa de Arriba celanovesa, la misma en la que tiempo atrás había nacido ese otro poeta gallego fundamental que fue Manuel Curros Enríquez. Para sus padres, Venancio Ferreiro Reinoso, de profesión comerciante, y Obdulia Miguez Buján, propietaria de diversas tierras y natural

\footnotetext{
${ }^{\text {I }}$ Para citar este artículo: Nicolás Rodríguez, Ramón (2OI2). Celso Emilio Ferreiro: voz de un tiempo y una tierra a los cien años de su nacimiento. Alabe 6 [www.revistaalabe.com] (Recibido O4/IO/2OI2; aceptado OI/II/2OI2)

${ }^{2}$ La mayor parte de los datos e informaciones que se ofrecen en este artículo beben de un trabajo más amplio de mi autoría que vió la luz bajo el título de Onde o mundo se chama Celso Emilio Ferreiro (Edicións Xerais, Vigo, 620 páginas, 20I2).
} 
de Acevedo do Río, lugar perteneciente hoy al municipio de Celanova, Celso Emilio fue ya el último de sus hijos, a la sazón el menor de siete hermanos, y creció en un ambiente familiar nítidamente republicano y galleguista, no en vano su padre había pertenecido a las Irmandades da Fala, institución creada en r9ı6 que pondrá las bases del nacionalismo gallego del siglo XX. Las primeras letras las estudia con una maestra de la localidad, para continuar su formación con los Escolapios establecidos en el convento de San Rosendo de Celanova, con los que permanecerá entre ı19 у г929.

Movido por una sensibilidad cívica que siempre lo caracterizará contacta con los intelectuales que en Ourense mantenían la tertulia del Café Roma, donde conoce a las figuras del llamado "Grupo Nós" (Risco, Otero Pedrayo y Castelao). Su incorporación al movimiento galleguista es muy intensa y fervorosa, de manera que en I935 cofunda, junto con Xosé Velo Mosquera, las “Mocedades Galeguistas” del distrito de Celanova, donde desempeñó labores directivos por los que sufrirá un proceso judicial que quedaría sin efecto en febrero de I936. Antes de la guerra publica colaboraciones de manera habitual en revistas y semanarios como A Nosa Terra, A Fouce, Alento o Sery, en I936, echa a andar, nuevamente con Xosé Velo Mosquera, un proyecto novedoso: el coleccionable Cartafol de poesía, carpeta autoeditada en la que iban sumándose poemas de ambos autores y que eran remitidos a diversos amigos e interesados en la poesía gallega de aquel tiempo.

\section{La guerra civil}

Al poco del comienzo del conflicto fratricida, tras haber demostrado más de una vez su compromiso republicano intentando defender con las armas la legalidad republicana días previos a la rebelión militar, es llamado a filas con los demás mozos de su quinta. Tras no pocas tensiones familiares es obligado a incorporarse al ejército sublevado y se traslada al frente de Asturias donde redacta poemas en castellano, de carácter sentimental e intimista, algunos de ellos aún inéditos.

Su presencia en el frente de guerra se alargará durante un año y, más tarde, será destinado a Transmisiones en el edificio de la Telefónica de Oviedo. Por esta época, disfrutando de un permiso en Celanova se expresa en una tasca abiertamente sobre los efectos de la barbarie fascista y una vecina lo denuncia a las autoridades del lugar. El poeta es encarcelado y pasa cuatro días y tres noches en una celda del viejo convento celanovés, ahora convertido en cárcel provincial de los presos políticos; celda en donde se generan las vivencias presentes en su célebre poema "Larga noche de piedra", del libro homónimo. Conocedor del caso el Gobernador Militar de Ourense ordena su ejecución, que no llega a cumplirse gracias a la rápida intervención de sus familiares delante de las autoridades.

También en Asturias conoce, en septiembre de i937, a María Luisa Moraima Loredo, que estaba interna en un colegio de monjas y con quien se casará algunos años después en Gijón. De su unión nacerían cuatro hijos: Luís, José María, Isabel y Javier. 


\section{La posguerra: Celanova y Pontevedra}

Rematada la guerra retorna a Celanova. Allí, en compañía de su vecino y amigo Velo Mosquera, ejerce durante algún tiempo la docencia iniciando por libre estudios de Derecho y Magisterio, obteniendo el título de Maestro de Primera Enseñanza en la Escuela de Magisterio Masculina de Ourense en abril de 1946.

Su formación en Derecho le servirá para opositar y ganar el puesto primero de Secretario y después de Jefe de Justicia en la Fiscalía de Tasas de Pontevedra, donde trabajaría entre I94I y I950. Esta será una época especialmente prolífica en cuanto a la creación pues escribirá poemas, cuentos y artículos y se integrará en la vida cultural de la ciudad.

De i94I procede su poemario castellano Al aire de tu vuelo y de I947, con el sello de Ediciones Céltiga, Bailadas, cantigas y donaires, poemas neopopularistas prologados por Bouza-Brey y editados por Ramón Peña, amigo de Celso Emilio que tenía una pequeña imprenta en la que se editaba la revista Sonata Gallega (I944-I952). Además tuvo responsabilidades directas en Finisterre (I943-1946), revista dirigida por Emilio Canda, figurando en la misma como su redactor-jefe. Desde r945 colaborará intensamente en el semanario pontevedrés Ciudad, y en r959 comandará, junto con Emilio Álvarez Negreira y Manuel Cuña Novás, la colección "Benito Soto" de poesía: primera empresa editorial que daría a conocer poemarios en gallego en la posguerra. Es ahí donde se editaría Musa alemá (I95I), antología de quince composiciones de diversos poetas alemanes traducidos por Antonio Blanco Freijeiro y versionados al gallego por el propio Celso Emilio.

Vigo

En octubre de 1949 Celso Emilio obtiene el título de Procurador de los Tribunales y marcha a Vigo para ejercer como tal, compaginando su trabajo con el de accionista en una oficina de seguros sociales primero y con el de director de un taller de fotograbado después. En esta época comienza a colaborar en las páginas del rotativo Faro de Vigo, periódico en el que mantendrá secciones fijas al largo de su vida. Las más llamativas fueron aquellas que se agruparon bajo el epígrafe de "La Jaula de los Pájaros Raros”, que pensaba publicar posteriormente en forma de libro con un prólogo de Camilo José Cela.

En el año 1954 publica Curros Enríquez. Biografía y, como poeta, da a conocer el poemario Voz y voto (I955), y O soño sulagado (I955) en el que ofrece un conjunto de composiciones que van desde la recreación de la esfera más íntima del poeta, pasando por exhibir una valiente actitud beligerante con la realidad de su tiempo hasta incluso la inclusión de poemas con una tonalidad sarcástica. A este, que fue su primer poemario independiente en lengua gallega, le seguirán Longa noite de pedra (I962), publicado inicialmente en la Editorial Galaxia aunque su proyección posterior aumentaría con las siguientes ediciones bilingües realizadas, a partir de I968, desde la colección poética de El Bardo, editorial que dirigió José Batlló; este volumen supuso la consagración definitiva del poeta obteniendo un reconocimiento unánime tanto por parte de lectores como de crítica, lo que le convirtió en el poeta de referencia en el sistema literario gallego hasta 
fines de la década de los setenta y uno de los más leídos.

Celso Emilio desarrollará en estas fechas una intensa actividad cultural y política, en un primer momento en la órbita del clandestino Partido Comunista en Galicia y, poco después, en julio de I964, como un de los diez miembros fundadores del partido nacionalista Unión do Povo Galego (UPG), a la que pertenecerá hasta su ruptura definitiva en septiembre de 1974 .

\section{Caracas}

Por otro lado, a comienzos de I966, Celso Emilio recibe una invitación para pronunciar unas conferencias en la Hermandad Gallega de Caracas y para hacerse cargo de la Secretaría de Cultura de aquella sociedad. El poeta valora su situación personal y familiar, a lo que se añaden las presiones derivadas de su participación en la política clandestina que también afectaba a la marcha de sus negocios y de su economía, lo que lo llevó a aceptar aquella invitación. Esta decisión provoca que sus amigos más próximos dispongan un homenaje de despedida al poeta, acto que se convirtió en un importante acto de protesta, tal vez el acto reivindicativo de mayor alcance en aquellos tiempos, delante de la medida del gobierno de Franco de inundar las fecundas tierras de Castrelo de Miño (Ourense) para beneficiar los intereses de la empresa FENOSA.

El poeta arriba a Venezuela con ánimos renovados, acreditando en la potencialidad de la colectividad gallega emigrada entre tanta miseria cultural y socio-política de la Galicia que acababa de despedir. En el seno de la Hermandad se ocupará de la dirección, redacción y confección del periódico quincenal "Irmandade" y de otras actividades. En este sentido, para dotarle de una mayor intensidad a las actividades de la Hermandad, fundará y presidirá desde r967 la “Agrupación Nós”, entidad que pretendía dotar de un sesgo nacionalista a algunas actividades de la Hermandad. Sin embargo, la directiva de la sociedad y el trabajo de Celso Emilio Ferreiro se van a ver amenazados por una facción de la institución que, de ideología fascista y próxima al gobierno de Franco, pretende acabar con esta labor cultural, apuntando con sus dardos a la figura de Celso Emilio, quien será injustamente expulsado de esta institución junto con su hijo Luís Ferreiro.

Poco después Celso Emilio crea, junto con algunos otros amigos alejados de la Hermandad, el "Padroado da Cultura Galega”, en el que desempeñará las labores de secretario general, asociación que en seguida se revelará infructuosa y acabará por abandonarla. Nuestro autor se ve en el deber de comenzar un periplo laboral en el que realizará labores docentes en una academia y, más tarde, trabajos como corrector de pruebas en la imprenta de un gallego emigrado. Con todo, merced a su amigo y poeta Antidio Cabal, en I97O, accede al puesto de corrector de estilo en el Gabinete de Prensa de la Oficina Central de Información del presidente Rafael Caldera. Desde ese momento y hasta su regreso a España, su situación laboral y familiar quedó salvaguardada, por más que se llegara incluso a filtrar a periódicos gallegos la falsa noticia de su muerte. 
Este es el contexto en el que se generan poemarios como Viaxe ao país dos ananos (I968) que, en su primera parte, constituye un ataque a esos emigrantes ajenos a lo que no fuera obtener lucro personal. Y aún ahonda el poeta en esta línea, publicando en Caracas ese mismo año Cantigas de escarño e maldicer, bajo el heterónimo satírico de Arístides Silveira. A este último libro se añadiría poco después Os autentes (I973).

En esta línea satírica-reivindicativa se hace necesario situar el poemario, en castellano a pesar del título, Fóronse á puñeta (I973) firmado con el nombre de Neskezas Cokhan Mordhe, surgido como despedida de los entonces directivos salientes de la Hermandad, además del célebre romance de ciego Paco Pixiñas (I970).

Aún pertenecería a este ciclo de poesía satírica su libro de epitafios jocosos $C e$ menterio privado, publicado en I973 por Ediciós Roi Xordo en Ginebra y, algunos años antes Tierra de ningures (I969) al que se sumarán títulos editados en Caracas que contienen poemas censurados en España como 13 poemas iracundos y una canción inesperada, separata de la revista caraqueña Expediente, o en 1972 Poemas prohibidos. Diez poemas no incluidos en el libro "Antipoemas" por causas no imputables a la voluntad del autor.

Celso Emilio hurta tiempo a sus ocupaciones y buscar otra vía de expresión literaria en lengua gallega con la prosa, inspirándose en los años de su estadía venezolana con los relatos recogidos en $A$ fronteira infinda $\left(\mathrm{I}_{972}\right)^{3}$.

De entre su prolífica producción poética muchas de sus composiciones poéticas fueron utilizadas como letras de canciones, sobre todo desde el nacimiento del movimiento musical llamado Nova Canción Galega.

\section{El retorno: Galicia, Madrid, Galicia}

En r973 Celso Emilio llega a Madrid, y no a Galicia, donde se le cerraron algunas puertas, más de las que esperaba. En la capital le aguarda un trabajo como redactor en la revista Tribuna médica, de la que era presidente del consejo de administración el empresario y mecenas lucense Álvaro Gil.

Este trabajo va a simultanearlo con su dedicación al Ateneo Científico, Literario y Artístico de Madrid, en el que desempeñará el cargo de Director del aula de Cultura en la sección de Literatura Gallega desde julio de I974.

Publica, además, en edición bilingüe e impreso por Editora Nacional, Onde o mundo se chama Celanova (1975), libro en el se acoge a un discurso emocional en clave sentimental y evocadora, en el que Celanova se erige como su particular paraíso perdido. Una obra que le valdría el Premio de la Crítica de Poesía Gallega de r976.

También de estos años data el opúsculo titulado Al César enano (I975), recopilación firmada bajo el seudónimo de Stow Kiwotto Lumen y que recoge una docena de versos antifranquistas del poeta escritos entre r96r y el momento de su publicación. En el campo

\footnotetext{
${ }^{3}$ Existe una edición en castellano realizada por Faktoría K de Libros, con el título de La frontera infinita del año 2007.
} 
de la prosa daría a imprenta en Ediciones Castrelos A taberna do galo4 (i978), que no son unas "memorias en un sentido estricto, sino que se trata de unas memorias imaginadas basadas en hechos reales".

Además dispone la Antología (r977) bilingüe para Plaza y Janés de Barcelona -única antología esta, junto con la portuguesa Autoescolha poética (I954-I97I), de I972-, realizadas bajo su supervisión. Posteriormente vigilará de cerca la publicación de los primeros volúmenes de su Obra completa (ı975, vols. I y II, I98I vol. III) para la madrileña Akal, y así hará también con la versión corregida y aumentada para Ediciones Júcar de Gijón de su biografía sobre Curros Enríquez (1973).

Su retorno sirvió también para que su figura fuera reclamada desde los más distintos foros, encuentros, congresos y homenajes. Retoma también las colaboraciones en algunos periódicos, destacando la sección fija que mantuvo en el ABC entre diciembre de r977 y agosto de 1979 bajo el epígrafe de "Mirador Literario: Escrito en Gallego", en la que iba desgranando las novedades literarias que en Galicia se producían.

Por otro lado, desvinculado de la U.P.G. en I974, concurre como candidato del frente multipartidista Candidatura Democrática Galega a un escaño de senador por la provincia de Ourense en las primeras Elecciones Generales de I977. Implicado de lleno en este proceso electoral, participa en la campaña dando mítines y recitando el "Romance eleutoral do cego de Trasmiras", antes de acercarse en sus últimos días a la órbita del PSOE.

El 3I de agosto de I979 fallece en su casa de Vigo y el sábado I de septiembre son trasladados sus restos a Celanova, recibiendo sepultura en otro acto cívico acompañado de más de dos millares de personas.

Tras su muerte aún se publicó el Libro das homenaxes (I979), que el había dejado ya dispuesto para su publicación y, dos años más tarde, la editorial gijonesa Júcar editaba los relatos de El alcalde y otros cuentos, autotraducción al castellano de los cuentos que componían el ya citado $A$ fronteira infinda con alguna adición.

Desde aquella fecha se sucederán los homenajes a su memoria destacando la realizada en el Polideportivo del Sar en Santiago de Compostela en el mes de octubre de i979 y el convocado el 3 de noviembre de ese año en el Palacio de los Deportes de Madrid. En r98I el Ayuntamiento de Vigo instituyó el Premio de Poesía Celso Emilio Ferreiro y, por ese mismo tiempo, se creaba en Santiago la Fundación del mismo nombre, que desarrolla hasta hoy un papel clave para el reconocimiento y difusión de su producción poética y de su biografía.

Por otro lado, en 1989 se le dedica el Día de las Letras Gallegas lo que sirvió para actualizar y potenciar su obra literaria. En 2004, al celebrarse el vigésimo quinto aniversario de su muerte, fueron numerosas las actividades que reivindicaron su memoria y su obra literaria -congresos, reediciones de sus libros, conferencias...- para que las generaciones que no lo trataron, y sólo pudieron conocerlo a través de sus poemas, admirasen ese edificio literario que fue construyendo despacio y que así nos legó, siendo considerado unánimemente como una de las cimas de nuestro sistema literario.

${ }^{4}$ Con traducción al castellano, en el sello asturiano Pez de Plata, en el 20 II. 


\section{Su poesía y Longa noite de pedra}

Polifonía, diversidad, intensidad, sentido y ritmo musicales, incorporación de discursos coloquiales, pluralidad de registros -intimista, reivindicativo, sarcástico e irónico-, cuidado formal..., son sólo algunos de los adjetivos que pueden resultar operativos para definir su obra poética.

Sus orígenes como poeta, sin duda influenciados tanto por el conocimiento de la riquísima tradición oral gallega de manos dadas con las lecturas realizadas en la biblioteca familiar, determinan la voz de un poeta, nacido en la República al amparo de la sombra proyectada por los poetas vanguardistas gallegos de la época y que ya en $O$ soño sulagado, publicado en I955, daba cuenta de su particular concepción poética como un todo unitario, encerrando una sorprendente unidad temática y estilística asumida por un autor que, como si se tratara de un plan minuciosamente diseñado, va a ir siguiendo desde la publicación de este que fue su primer poemario en gallego. Aquí están, por tanto, poemas que ahondan en el dolor que produce la propia existencia; composiciones regidas por la contención pero en las que no olvida derramar su visión solidaria delante de las injusticias.

De todo esto nos encontramos, en mayor o menor medida, en su obra poética global, en el citado Viaxe ao País dos Ananos, en Cemiterio privado, en Onde o mundo se chama Celanova y, por supuesto también, en su Longa noite de pedra, pues en este poemario, del que se celebra también el cincuenta aniversario de la publicación de su primera edición en la editorial Galaxia, adopta una perspectiva desde la que enlaza con la tradición reivindicativa de la poesía gallega del siglo XIX, sobre todo con los modelos ofrecidos por Curros y Rosalía que el supo revitalizar y actualizar.

Dueño de una visión universalista y abierta, Celso Emilio persigue siempre construir un discurso en el que analiza la realidad gallega, castigada y enajenada históricamente, sembrando aquí y allá numerosas referencias, que lograron pasar la censura previa un tanto sorprendentemente sobre todo las que atañen a las huellas de la guerra civil española y al relato de la opresión fascista, al mundo de la emigración o a la reflexión sobre la suerte de su propio país y de sus gentes con una inequívoca voluntad de agitación y lucha política.

Pero no sólo es así su poesía: también hay lugar para el intimismo, que no oculta el sentimiento de desarraigo y de vacío. Celso Emilio expresa la vivencia angustiosa de su tiempo, producida tanto por la pérdida de un paraíso ideal experimentado en la infancia y por el paso del tiempo. Y aún hay más: el registro irónico que en ocasiones manifiesta literariamente bien se podría entender como una de las posibles salidas delante de la contradicción que padece el poeta: ahí nace el Celso Emilio Ferreiro antipoeta, el que defiende la poesía social, potenciando el interés por expresarse en un registro común, en ocasiones coloquial, para desvestir a la poesía de su trascendencia, para volver a imprimirle su carácter comunicativo esencial. Esta es, en mi opinión, una de las claves que explican, en Galicia, la vigencia generalizada de su poesía. 